\title{
Effect of basic factors of extender composition on post-thawing quality of brown bear electroejaculated spermatozoa
}

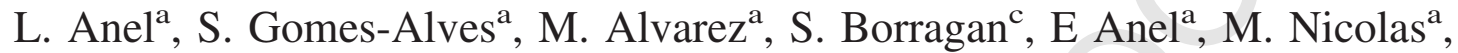 \\ F. Martinez-Pastor ${ }^{\mathrm{d}}$, P. de Paz ${ }^{\mathrm{b}, *}$ \\ ${ }^{a}$ Animal Reproduction and Obstetrics, University of León, 24071 León, Spain \\ ${ }^{\mathrm{b}}$ Cell Biology, University of León, 24071 León, Spain \\ ${ }^{\mathrm{c}}$ Cabarceno Park, Cantabria, Spain \\ ' INDEGSAL and Molecular Biology, University of León, 24071 León, Spain
}

Received 28 November 2009; received in revised form 1 March 2010; accepted 7 March 2010

\begin{abstract}
The improvement of freezing extenders is critical when defining sperm cryopreservation protocols for wild species, in order to create germplasm banks. The aim of this study was to evaluate the effect of additives (Equex Paste and EDTA) supplementation, egg-yolk (10 and 20\%) and glycerol (4 and 8\%) concentrations and extender osmolality (300 and $320 \mathrm{mOsm} / \mathrm{kg}$ ) on the post-thawing quality of brown bear semen. Semen was obtained from 20 adult males by electroejaculation, and centrifugated individually $(600 \times \mathrm{g}$ for $6 \mathrm{~min})$. The pellets were diluted 1:1 in the corresponding extender TTF (TES-Tris-Fructose with the aforementioned variants) and cooled to $5^{\circ} \mathrm{C}$. Then, it was diluted down to $100 \times 10^{6} \mathrm{spz} / \mathrm{mL}$, loaded in $0.25 \mathrm{~mL}$ straws and frozen at $-20^{\circ} \mathrm{C} / \mathrm{min}$. After thawing (in water at $65^{\circ}$ $\mathrm{C}$ for $6 \mathrm{~s}$.), the semen samples were assessed for motility (CASA), viability (SYBR-14 with propidium iodide), acrosomal status (PNA-FITC with propidium iodide) and mitochondrial activity (JC-1). Extender supplementation with additives rendered significantly higher results for these sperm parameters. Comparing the two percentages of egg yolk, $20 \%$ egg yolk showed the highest motility results, percentages of viable spermatozoa and viable spermatozoa with intact acrosome. No differences were detected among samples frozen using 4 or $8 \%$ glycerol. For extender osmolality, $300 \mathrm{mOsm} / \mathrm{kg}$ showed higher values of VAP, VCL, VSL, and ALH than $320 \mathrm{mOsm} / \mathrm{kg}$. Based on the best performance of sperm motility, viability and acrosome status, we conclude that the most suitable extender to cryopreserve brown bear spermatozoa was TTF adjusted to $300 \mathrm{mOsm} / \mathrm{kg}$, supplemented with $20 \%$ egg yolk, 4-8\% glycerol, and the additives 1\% Equex paste and 2\% EDTA.
\end{abstract}

() 2010 Published by Elsevier Inc.

Keywords: Brown bear; Cryopreservation; Spermatozoa; Extender; Germplasm banks

\section{Introduction}

Genetic resource banks (GRBs) are a valuable tool for the conservation of threatened or endangered species and valuable breeds [1,2]. Some populations of

\footnotetext{
* Corresponding author.

E-mail address: ppazc@unileon.es (P. de Paz).
}

brown bear are currently endangered, and are a possible target for germplasm banking in order to aid their protection. This could be the case of grizzly bears (Ursus arctos horribilis), considered threatened outside of Alaska by the Threatened Species Conservation Act of the USA and Cantabrian brown bear (Ursus arctos), which is considered to be at risk of extinction (Royal Decree 439/1990 of the Spanish law, regulation of the 
National Catalogue of Endangered Species), and only survives in two small isolated populations in the Cantabrian mountains (Northern Spain).

Sperm cryopreservation is usually the first approach in establishing a germplasm bank for the preservation of this species [3]. However, the most important challenge for establishing GRBs is the lack of knowledge on specific sperm traits, which are critical for an adequate protocol design [4].

According to Anel et al. [5], brown bear sperm can be considered that freezes well. The adjustment of a cryopreservation protocol requires the study of several factors affecting the success of the freezing process [6] particularly with regard to the formulation of a specific extender to the characteristics of brown bear ejaculates. There are a few reports on bear semen cryopreservation employing extenders already used in other species, which rendered good results: Tris-buffered-egg-yolk in Hokkaido brown bear sperm [7], Tris-citric acid-glucose-egg yolk in Japanese black bear sperm [8], egg yolk-lactose [9] or TES-Tris-egg yolk [10,11] in giant panda sperm. Nevertheless, due to the great biological value and scarcity of sperm samples obtained from wild, endangered animals, it is necessary to optimize these extenders for the species, in order to improve post-thawing sample quality [5].

Extender composition includes buffer systems, cryoprotectants, sugars, and other additives, which are supposed to protect spermatozoa, providing energy substrates and preventing deleterious effects of changes in $\mathrm{pH}$ and osmolality $[12,13]$. Among the most common components of semen diluents for mammals are egg yolk and glycerol. Egg yolk is beneficial to sperm cryopreservation because it protects against cold shock [12], and has been included routinely in most extenders for frozen semen from domestic animals as well as several wild species at different concentrations (in $\mathrm{Cu}$ vier's gazelle semen from 5\% to 20\% [14]). However, several studies revealed that higher egg yolk concentrations in some species negatively affected preservation of motility and acrosome integrity during cryopreservation [15] or reduce post-thawing viability [16]. In bear sperm, egg yolk has been used at different concentrations: $15 \%$ [7] or $20 \%$ [17].

Concentrations of glycerol ranging from 2 to $10 \%$ have been used to cryopreserve mammalian spermatozoa. Glycerol, despite its value as cryoprotectant, can be toxic to spermatozoa at high concentrations [18]. For bear sperm cryopreservation, glycerol is the main cryoprotectant used in extenders and the cryoprotective ef- fect of concentrations from $4 \%$ to $8 \%$ has been assayed in different bear species $[7,8,9,10,11,19]$.

To develop an optimal extender, we must also consider the special characteristics of brown bear ejaculates. A high incidence of sperm agglutination was documented by Kojima et al. [20] and Anel et al. [5]. Agglutination makes semen assessment and handling difficult and can influence sperm freezability [5], although it has been reported that it did not interfere with fertility results in boars [21]. Therefore, the extender composition needs to be improved in order to reduce this problem. One of the options explored in the present study was the addition of a surfactant (Equex paste) and a calcium chelator (EDTA) to the freezing diluents. Studies in other species have shown the beneficial effects of these substances on semen: dog [22-25], cat [26], boar [27], stallion [28], bull [29], and deer [30].

Media osmolality is another important factor that can influence the outcome of the cryopreservation process. The adjustment of extender osmolality is of great importance because of its influence on the dehydration, rehydration, and intracellular crystal formation to which spermatozoa are subjected during the cryopreservation process [30].

Anel et al. [32] suggested that an extender used for ram semen freezing (TES-Tris-fructose-10\% egg-yolk$4 \%$ glycerol) rendered good results for motility and viability of brown bear spermatozoa. In fact, this extender was successfully used for freezing semen from different wild species: somalia wild ass [33], iberian red deer [34], blue wildebeest [35]. In this regard, based on a preliminary study carried out by our group in brown bear ejaculates with the above mentioned extender, we propose to assay four variants of that extender, aiming at adjusting its composition to the characteristics of brown bear ejaculates. In a first experiment we conducted three different assays to evaluate: the use of Equex paste and EDTA, two concentrations of egg-yolk (10 and $20 \%$ ) and two glycerol concentrations (4 and $8 \%$ ). In a second experiment we carried out a study of the use of two extenders with different osmolality $(300 \mathrm{mOsm} / \mathrm{kg}$ and $320 \mathrm{mOsm} / \mathrm{kg}$ ).

\section{Material and methods}

All the chemicals were at least of reagent grade, and they were obtained from Sigma (Madrid, Spain), unless otherwise stated. 


\subsection{Animals and sample collection}

Animal handling was performed in accordance with Spanish Animal Protection Regulation RD223/1998, which conforms to European Union Regulation 86/609. Sixty semen samples from 20 sexually mature male brown bears were obtained by electroejaculation during the breeding season (end of April to early July). The animals were housed in a half-freedom regime in Cabarceno Park (Cantabria, Spain; $43^{\circ} 21^{\prime} \mathrm{N}, 3^{\circ} 50^{\prime}$ $\mathrm{W}$; altitude: $143 \mathrm{~m}$ ), and fed on a diet based on chicken meat, bread, and fruits.

The males were immobilized by teleanaesthesia, using zolazepam $\mathrm{HCl}$, tiletamine $\mathrm{HCl}$ (Zoletil100 ${ }^{\circledR}$; Virbac, Carros, France) $7 \mathrm{mg} / \mathrm{kg}$, and ketamine (Imalgene $1000^{\circledR}$; Rhone-Mérieux, Lyon, France) $2 \mathrm{mg} / \mathrm{kg}$. After immobilization, the males were weighed and monitored (pulse, oxygen saturation, and respiration). Prior to electroejaculation, the prepucial area was shaved and washed with physiological saline serum, and the rectum was emptied of feces. The bladder was catheterized during semen collection to prevent urine contamination. Electroejaculation was carried out with a PT Electronics ${ }^{\circledR}$ electroejaculator (PT Electronics, Boring, OR, USA). The transrectal probe was $320 \mathrm{~mm}$ long with a diameter of $26 \mathrm{~mm}$. Electric stimuli were given until ejaculation (10 V and $250 \mathrm{~mA}$, on average). The ejaculates were collected by fractions in graduated glass tubes. The fresh semen samples of brown bear yielded an average number of spermatozoa of $423.0 \pm 53.7 \times$ $10^{6}$ (mean $\pm \mathrm{SD}$ ). All ejaculates used in the present study have been selected to be urine-free, as explained below.

\subsection{Experimental design}

Semen cryopreservation was performed according to Anel et al. [32]: extender TES-Tris-Fructose with egg yolk, glycerol and antibiotics; cooling rate: $-0.25^{\circ}$ $\mathrm{C} / \mathrm{min}$ and freezing rate: $-20^{\circ} \mathrm{C} / \mathrm{min}$.

First, three different assays were carried out to test the addition of additives (Equex paste and EDTA), two glycerol concentrations and two egg-yolk concentrations, respectively. The effect of osmolarity was then evaluated in a fourth assay. The scarce number of total spermatozoa obtained by ejaculated, due to the loss of cells during centrifugation and the number of cells necessary for semen evaluation, made it impossible to design a multifactorial experiment to study these four parameters (additives, glycerol, egg-yolk, and osmolality). All semen samples were evaluated and frozen individually.

\subsubsection{Experiment 1}

This experiment was based on previous data that we obtained for brown bear ejaculates and on bibliographic reports $[7,8,10,22]$, therefore we used as base an extender composed by TES-Tris-Fructose [32]. In each assay, we used this extender analyzing two different combinations of each basic component: assay 1.1: addition or not of additives (1\% Equex paste and 2\% EDTA); assay 1.2: two percentages of egg-yolk (10$20 \%$ ) and assay 1.3: two glycerol concentrations (4$8 \%$ ). Antibiotics (penicillin and streptomycin) were added to each extender formulation. In all the assays, semen was divided in two aliquots to evaluate each combination.

\section{Assay 1.1: Additive supplementation}

Fifteen ejaculates obtained from eleven different bears were studied to evaluate the benefits of Equex paste (Minitüb, Germany) and EDTA added to the sperm cryopreservation extender. Ejaculates were divided in two aliquots (in all assays) and frozen either in the TTF extender [with 20\% egg-yolk and $8 \%$ glycerol at $320 \mathrm{mOsm} / \mathrm{kg}$ ] supplemented with additives or without additives (A and NA, respectively).

\section{Assay 1.2: percentages of egg-yolk}

To determine the best concentration of egg-yolk in the cryopreservation extender we used fourteen brown bear semen samples from seven males, which were frozen in the TTF extender [with $8 \%$ glycerol and $1 \%$ Equex paste $+2 \%$ EDTA at $320 \mathrm{mOsm} / \mathrm{kg}$ ] supplemented with $10 \%$ egg-yolk (Y10) or with $20 \%$ eggyolk (Y20).

\section{Assay 1.3: glycerol concentrations}

The effect of two glycerol concentrations on the post-thawing quality of brown bear spermatozoa was evaluated. Eleven ejaculated sperm samples were collected from 10 different bears and cryopreserved with each of two extenders: TTF [with $20 \%$ egg-yolk and $1 \%$ Equex paste $+2 \%$ EDTA at $320 \mathrm{mOsm} / \mathrm{kg}]$ supplemented with $4 \%$ glycerol (G4) or with $8 \%$ glycerol (G8).

\subsubsection{Experiment 2}

According to our results in Experiment 1, we defined an optimal extender: TTF, 20\% egg-yolk, 8\% glycerol and $1 \%$ Equex paste $+2 \%$ EDTA, which was applied in a final assay to test the effect of osmolality. 


\section{Assay 2.1: Extender osmolality}

Twenty ejaculates from fifteen males were used to test the effect of extender osmolality on brown bear sperm cryopreservation. Samples were processed with TTF above mentioned either adjusted to 300 or to 320 $\mathrm{mOsm} / \mathrm{kg}$ (E300 and E320, respectively).

\subsection{Semen cryopreservation}

Immediately after collection, the volume of each ejaculate was recorded, osmolality was measured using a cryoscopic osmometer (Osmomat-030, Gonotec TM; Berlin) and the $\mathrm{pH}$ value was determined by $\mathrm{pH}$ meter (CG 837-Schott; Germany). For each ejaculate, sample motility was assessed with a phase contrast microscope and urospermia was evaluated by means of a rapid urea test (Merckgnost Urea Rapid Screening test, Merck, Barcelona, Spain). Samples of low motility $(<50 \%)$ or urine contaminated samples $(>80 \mathrm{mg}$ urea/dL) were rejected [36]. The selected samples were divided into two aliquots and centrifuged at $600 \times \mathrm{g}$ during $6 \mathrm{~min}$. The supernatant was discarded and each pellet was diluted with an equal volume of the corresponding extender, depending on the experiment, at room temperature. Tubes with the diluted semen were put in glasses containing $100 \mathrm{ml}$ of water at room temperature and transferred to refrigerated container to $5^{\circ} \mathrm{C}$, so temperature decreased slowly to $5^{\circ} \mathrm{C}$ (70-80 $\left.\mathrm{min}\right)$. Once at $5^{\circ} \mathrm{C}$, the samples were diluted again $1: 1$ with the same diluents prepared with a higher glycerol concentration (6\% for the G4 assay and $12 \%$ for the others), in order to achieve a final glycerol concentration for each extender (4\% and $8 \%$, respectively). The samples were diluted with the original extender ( $4 \%$ glycerol for the G4 assay and 8\% for the others) to yield a final concentration of $100 \times 10^{6}$ spermatozoa $/ \mathrm{mL}$. After equilibration for $1 \mathrm{~h}$ at $5^{\circ} \mathrm{C}$, the semen was packaged into $0.25 \mathrm{~mL}$ plastic straws, and frozen in a programmable biofreezer (Kryo 10-16 II PlanerTM) at $-20^{\circ} \mathrm{C} / \mathrm{min}$ down to $-100^{\circ} \mathrm{C}$, and then transferred to liquid nitrogen containers. The cryopreserved samples were stored in liquid nitrogen for a minimum of one week. Thawing was performed by plunging the straws in water at $65^{\circ} \mathrm{C}$ for $6 \mathrm{~s}$ and the sample are evaluated immediately at room temperature.

\subsection{Semen evaluation}

Before freezing and after thawing, the semen samples were analyzed for sperm agglutination, motility, viability, acrosomal status and mitochondrial activity.
Sperm agglutination was evaluated on a microscope slide by subjective observation under a phase contrast microscope and rated on a scale from 0 to 4: 0 -absence of agglutination; 1-low degree of agglutination $(<10 \%$ agglutinated sperm); 2-intermediate level of agglutination (10-30\%); 3-high degree of agglutination (30$50 \%)$ and 4-very high degree of agglutination $(>50 \%)$.

Motility parameters were assessed by means of a computer-assisted sperm analysis system (CASA) (Sperm Class Analyzer; Microptic, Barcelona, Spain). Samples were diluted $\left(10-20 \times 10^{6}\right.$ cells $\left./ \mathrm{mL}\right)$ in an $1 \%$ buffer (HEPES $20 \mathrm{mmol} / \mathrm{L}, 197 \mathrm{mmol} / \mathrm{L} \mathrm{NaCl}, 2.5$ mmol/L KOH, $10 \mathrm{mmol} / \mathrm{L}$ glucose; $\mathrm{pH}$ 7; 300mOsm/ $\mathrm{kg}$ ), and warmed on a $37^{\circ} \mathrm{C}$ plate for $5 \mathrm{~min}$. Then, $5 \mu \mathrm{L}$ sperm sample was placed in a Makler counting cell chamber (10 $\mu \mathrm{m}$ depth; Sefi Medical Instruments, Haifa, Israel) and analyzed using a negative phase objective $(\times 10)$ in a contrast microscope with a warmed stage $\left(38^{\circ} \mathrm{C}\right)$. The standard parameter settings were as follows: 25 frames/s; 5 to $80 \mu \mathrm{m}$ [2] for head area; VCL $>10 \mu \mathrm{m} / \mathrm{s}$ to classify a spermatozoon as motile. At least fields and 200 spermatozoa were saved and analyzed afterwards. Reported parameters were total motility (TM), progressive motility (PM; VCL $>25$, STR $>80$ ), average path velocity (VAP, $\mu \mathrm{m} / \mathrm{s}$ ), curvilinear velocity (VCL, $\mu \mathrm{m} / \mathrm{s})$, straight-line velocity (VSL, $\mu \mathrm{m} / \mathrm{s}$ ) and amplitude of lateral head displacement (ALH, $\mu \mathrm{m})$. A detailed explanation of these motility parameters has been provided elsewhere [37].

To evaluate sperm viability, the double stain SYBR-14 with propidium iodide (LIVE/DEAD Sperm Viability Kit; Invitrogen, Barcelona, Spain) using flow cytometer was applied. Sperm samples were diluted with PBS down to $5 \times 10^{6}$ spermatozoa/ml, and 300 $\mu \mathrm{L}$ were transferred to a polypropylene tube to which we added $3 \mu \mathrm{L}$ PI $(24 \mu \mathrm{M})$ and $1.5 \mu \mathrm{L}$ SYBR-14 (100 $\mathrm{nM})$. The tubes were kept at $37^{\circ} \mathrm{C}$ for $20 \mathrm{~min}$ in the dark. We detected three populations corresponding to percentage of live spermatozoa (green), moribund spermatozoa (red + green) and dead spermatozoa (red). Only live spermatozoa (named VIAB) were recorded.

For acrosomal status, we used the double stain PNAFITC (PNA-FITC) and IP in a stock solution in PBS at $1 \mu \mathrm{g} / \mathrm{mL}$ and $24 \mu \mathrm{M}$, respectively. PNA is a lectin from Arachis hypogaea that binds to beta-galactose moieties associated with the outer acrosomal membrane of spermatozoa, indicating acrosome damaged cells. Sperm samples were diluted in PBS $\left(5 \times 10^{6}\right.$ spermatozoa/ $\mathrm{mL}$ ), and $300 \mu \mathrm{L}$ were transferred to a polypropylene tube to which we added PI $(24 \mu \mathrm{M})$ and PNA-FITC (1 $\mu \mathrm{g} / \mathrm{mL})$. Flow cytometer rendered the percentage of 
viable spermatozoa with intact acrosome (non red and non green fluorescence, ACR).

JC-1 (Invitrogen, Barcelona, Spain) was used to assed mitochondrial status, identifying mitochondria with high mitochondrial potential. Samples were diluted in $300 \mu \mathrm{L}$ of PBS $\left(5 \times 10^{6}\right.$ sperms $\left./ \mathrm{mL}\right)$, adding JC-1 at $6.8 \mu \mathrm{M}$. After $30 \mathrm{~min}$ at $37^{\circ} \mathrm{C}$, we obtained by flow cytometer the percentage of orange stained sperm (high membrane mitochondrial) named MIT.

Evaluation of flow cytometer parameters (viability, acrosomal status and mitochondrial status) was carried out using a FACScalibur flow cytometer (Becton Dickinson Systems, San Jose, CA, USA), equipped with standard optics and an argon ion laser, tuned at $488 \mathrm{~nm}$, and running at $200 \mathrm{~mW}$. Calibration was carried out periodically using standard beads (Calibrites; Becton Dickinson). 10,000 events with a flow rate of 200 cells/s were analyzed per sample.

\subsection{Statistical analysis}

Data were analyzed using the SAS ${ }^{\mathrm{TM}}$ V.9.0. package. The parameters of semen quality were the dependent variables and a GLM procedure was used to evaluate the effect of various factors: addition or not of additives, egg-yolk concentration, glycerol concentration and extender osmolality. Least-squares means were computed for each effect listed and P-values for differences of the multiple comparisons were calculated by Tukey's test. Changes on the frequencies of the agglutinated spermatozoa classification depending on additive supplementation were analyzed using a FREQ

\section{Table 1}

Post-thawing semen quality (mean \pm SEM) for supplementation or not with additives (Equex paste ${ }^{\circledR}$ and EDTA); (TTF* with or without additives corresponds to A and NA, respectively).

\begin{tabular}{lrrr}
\hline Parameters & \multicolumn{1}{c}{ A } & \multicolumn{1}{c}{ NA } & \multicolumn{1}{c}{ P } \\
\hline TM $(\%)$ & $53.9 \pm 3.5$ & $36.5 \pm 3.9$ & 0.021 \\
PM $(\%)$ & $28.1 \pm 3.3$ & $17.4 \pm 2.9$ & 0.018 \\
VAP $(\mu \mathrm{m} / \mathrm{s})$ & $60.0 \pm 3.4$ & $45.2 \pm 3.6$ & 0.005 \\
VCL $(\mu \mathrm{m} / \mathrm{s})$ & $107.2 \pm 6.3$ & $81.2 \pm 7.1$ & 0.010 \\
VSL $(\mu \mathrm{m} / \mathrm{s})$ & $45.3 \pm 3.3$ & $33.4 \pm 3.0$ & 0.011 \\
ALH $(\mu \mathrm{m})$ & $4.5 \pm 0.2$ & $3.5 \pm 0.3$ & 0.011 \\
VIAB $(\%)$ & $60.0 \pm 1.4$ & $44.1 \pm 2.4$ & $<0.001$ \\
ACR $(\%)$ & $63.5 \pm 1.9$ & $46.5 \pm 2.3$ & $<0.001$ \\
MIT $(\%)$ & $62.35 \pm 4.6$ & $45.6 \pm 4.3$ & 0.011 \\
\hline
\end{tabular}

TM: total motility; PM: progressive motility; VAP: average path velocity; VCL: curvilinear velocity; VSL: the straight line velocity; ALH: amplitude of lateral head displacement. VIAB: sperm viability; ACR: sperm with no damage acrosome within VIAB; MIT: spermatozoa mitochondrial membrane potential.

$\mathrm{P}$ indicates the difference between columns.

* TTF extender with $20 \%$ egg-yolk and $8 \%$ glycerol at $320 \mathrm{mOsm} / \mathrm{kg}$.

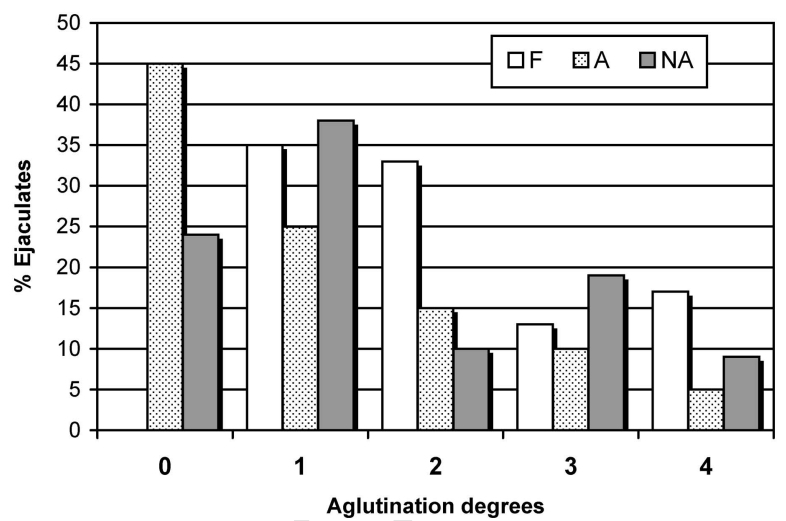

Fig. 1. Distribution (\%) of agglutination degrees (0-4) in fresh semen $(\mathrm{F})$ and post-thawed semen in extender with or without additives (A and NA, respectively).

Scale from 0-4: 0-absense of agglutination, 1-low degree of agglutination $(<10 \%$ agglutinated sperm), 2-intermediate level of agglutination $(10-30 \%)$, 3-high degree of agglutination $(30-50 \%)$ and 4-very high degree of agglutination $(>50 \%)$.

procedure. Values were considered to be statistically significant at $\mathrm{P}<0.05$.

\section{Results}

\subsection{Experiment 1}

The quality of post-thawed sperm was improved by extender supplementation with additives. Table 1 show that TTF with additives (A) rendered significantly higher results for all sperm parameters analyzed. Moreover, when we studied the effect of additives we observed that all of the fresh samples (F) showed agglutination (Fig. 1): most of the samples presented grades 1 or 2 of agglutination $(68 \%)$ and the rest of the ejaculates showed grades 3 or $4(32 \%)$. A gradual trend to decreasing agglutination levels in post-thawed samples was observed when we used the extender with additives (A), thus $45 \%$ of the samples did not present agglutination and 25\% manifested grade 1 agglutination (Tables 2 and 3). However, most of post-thawed samples frozen with the extender without additives (NA) showed grade 1 agglutination (38.1\%).

As in the case of supplementation with additives, there were significant differences between Y10 and Y20. Samples frozen with Y20 showed better postthawing mean values for all motility parameters, being significantly higher for all of them except: VCL ( $\mathrm{P}=$ $0.057)$ and ALH $(P=0.155)$. With regard to fluorescence parameters, Y20 showed significantly higher re- 
Table 2

Post-thawing semen quality (mean \pm SEM) for the two egg-yolk concentrations (TTF * with $10 \%$ or $20 \%$ egg-yolk; Y10 and Y20, respectively).

\begin{tabular}{lcrr}
\hline Parameters & \multicolumn{1}{c}{ Y10 } & \multicolumn{1}{c}{ Y20 } & \multicolumn{1}{c}{ P } \\
\hline TM $(\%)$ & $22.2 \pm 3.5$ & $53.6 \pm 4.6$ & $<0.001$ \\
PM $(\%)$ & $7.4 \pm 1.6$ & $25.2 \pm 3.0$ & $<0.001$ \\
VAP $(\mu \mathrm{m} / \mathrm{s})$ & $42.8 \pm 5.3$ & $61.2 \pm 3.7$ & 0.009 \\
VCL $(\mu \mathrm{m} / \mathrm{s})$ & $87.5 \pm 10.6$ & $112.4 \pm 6.7$ & 0.057 \\
VSL $(\mu \mathrm{m} / \mathrm{s})$ & $28.6 \pm 3.9$ & $42.3 \pm 3.1$ & 0.010 \\
ALH $(\mu \mathrm{m})$ & $3.8 \pm 0.4$ & $4.5 \pm 0.3$ & 0.155 \\
VIAB $(\%)$ & $31.1 \pm 5.1$ & $58.4 \pm 3.8$ & $<0.001$ \\
ACR $(\%)$ & $33.7 \pm 4.5$ & $62.5 \pm 3.7$ & $<0.001$ \\
MIT $(\%)$ & $30.5 \pm 8.3$ & $55.8 \pm 9.3$ & 0.053 \\
\hline
\end{tabular}

TM: total motility; PM: progressive motility; VAP: average path velocity; VCL: curvilinear velocity; VSL: the straight line velocity; ALH: amplitude of lateral head displacement. VIAB: sperm viability; ACR: sperm with no damage acrosome within VIAB; MIT: spermatozoa mitochondrial membrane potential.

$\mathrm{P}$ indicates the difference between columns.

* TTF extender with $8 \%$ glycerol and $1 \%$ Equex paste $+2 \%$ EDTA at $320 \mathrm{mOsm} / \mathrm{kg}$.

sults for VIAB and ACR, whereas significance was not found for MIT $(\mathrm{P}=0.053)$.

\subsection{Experiment 2}

For the extender osmolality experiment, osmolality of electroejaculated samples was $308 \pm 38 \mathrm{mOsm} / \mathrm{kg}$ (mean $\pm \mathrm{SD})$.

The comparison of the effect of the two extenders, E300 and E320, with different osmolalities, on quality

Table 3

Post-thawing semen quality (mean \pm SEM) for the two glycerol concentrations (TTF* with $4 \%$ or $8 \%$ glycerol, G4 and G8, respectively).

\begin{tabular}{lccl}
\hline Parameters & G4 & G8 & P \\
\hline TM $(\%)$ & $45.8 \pm 7.1$ & $48.6 \pm 5.4$ & 0.758 \\
PM $(\%)$ & $25.3 \pm 4.6$ & $25.1 \pm 4.6$ & 0.976 \\
VAP $(\mu \mathrm{m} / \mathrm{s})$ & $87.5 \pm 6.5$ & $84.5 \pm 8.0$ & 0.769 \\
VCL $(\mu \mathrm{m} / \mathrm{s})$ & $158.3 \pm 12.3$ & $164.7 \pm 14.9$ & 0.747 \\
VSL $(\mu \mathrm{m} / \mathrm{s})$ & $72.0 \pm 6.0$ & $67.7 \pm 7.4$ & 0.661 \\
ALH $(\mu \mathrm{m})$ & $6.3 \pm 0.5$ & $7.0 \pm 0.6$ & 0.412 \\
VIAB $(\%)$ & $34.9 \pm 3.0$ & $43.7 \pm 4.1$ & 0.097 \\
ACR $(\%)$ & $41.2 \pm 2.9$ & $48.3 \pm 3.8$ & 0.152 \\
MIT $(\%)$ & $43.6 \pm 3.0$ & $40.9 \pm 5.6$ & 0.670
\end{tabular}

TM: total motility; PM: progressive motility; VAP: average path velocity; VCL: curvilinear velocity; VSL: the straight line velocity; ALH: amplitude of lateral head displacement. VIAB: sperm viability; ACR: sperm with no damage acrosome within VIAB; MIT: spermatozoa mitochondrial membrane potential.

$\mathrm{p}$ indicates the difference between columns.

* TTF extender with $20 \%$ egg-yolk and $1 \%$ Equex paste $+2 \%$ EDTA at $320 \mathrm{mOsm} / \mathrm{kg}$.
Table 4

Post-thawing semen quality (mean \pm SEM) for the two extender osmolalities (E300 and E320 correspond to TTF* adjusted to 300 or $320 \mathrm{mOsm} / \mathrm{kg}$ ).

\begin{tabular}{lrrl}
\hline Parameters & \multicolumn{1}{c}{ E300 } & \multicolumn{1}{l}{ E320 } & \multicolumn{1}{l}{ P } \\
\hline TM $(\%)$ & $55.5 \pm 2.9$ & $51.5 \pm 3.2$ & 0.360 \\
PM $(\%)$ & $28.8 \pm 2.2$ & $23.7 \pm 2.1$ & 0.095 \\
VAP $(\mu \mathrm{m} / \mathrm{s})$ & $73.1 \pm 3.7$ & $60.7 \pm 3.5$ & 0.019 \\
VCL $(\mu \mathrm{m} / \mathrm{s})$ & $133.3 \pm 7.0$ & $111.4 \pm 6.2$ & 0.022 \\
VSL $(\mu \mathrm{m} / \mathrm{s})$ & $53.5 \pm 3.5$ & $42.8 \pm 2.8$ & 0.021 \\
ALH $(\mu \mathrm{m})$ & $5.4 \pm 0.3$ & $4.6 \pm 0.2$ & 0.032 \\
VIAB $(\%)$ & $61.6 \pm 2.4$ & $56.7 \pm 3.2$ & 0.218 \\
ACR $(\%)$ & $63.5 \pm 2.3$ & $61.1 \pm 2.6$ & 0.483 \\
MIT $(\%)$ & $55.9 \pm 5.8$ & $56.7 \pm 5.9$ & 0.923 \\
\hline
\end{tabular}

TM: total motility; PM: progressive motility; VAP: average path velocity; VCL: curvilinear velocity; VSL: the straight line velocity; ALH: amplitude of lateral head displacement. VIAB: sperm viability; ACR: sperm with no damage acrosome within VIAB; MIT: spermatozoa mitochondrial membrane potential.

$\mathrm{p}$ indicates the difference between columns.

* TTF extender with $8 \%$ glycerol, 20\% egg-yolk and 1\% Equex paste $+2 \%$ EDTA.

parameters of post-thawed brown bear semen is shown in Table 4. We observed that post-thawed semen parameters were significantly lower for E320 than for E300 extender: $\operatorname{VAP}(\mathrm{P}=0.019), \mathrm{VCL}(\mathrm{P}=0.022)$, $\operatorname{VLS}(\mathrm{P}=0.021)$ and ALH $(\mathrm{P}=0.032)$. For the other parameters, the results were similar for both extenders.

\section{Discussion}

The choice of adequate extenders and freezing protocols is a crucial point for the success of semen cryopreservation in any species. Extender composition includes buffer systems, cryoprotectants, sugars, and other additives, which interact with the cell membrane during the freezing-thawing process in a very specific way. Because of this, several combinations were proposed for the different species.

Different extenders formulated for other species were used for bear sperm cryopreservation [7,8,9, 10,19]. Although the results of sperm quality obtained were satisfactory, it is necessary to adjust the extender composition to bear semen characteristics. In the present work, the use of an extender manufactured in our laboratory with a known composition allowed the levels of its constituents to be easily adjusted [32].

To our knowledge, no studies have been carried out to analyze the effect of additives on bear semen quality during cryopreservation. In order to improve the postthawing quality of these samples we proposed that the extender be supplemented with additives (1\% Equex paste and 2\% EDTA) and we observed a significant 
improvement in sperm sample quality. Equex paste is a commercially available additive for use with semen extenders. It contains a detergent, sodium dodecyl sulphate (SDS), which might interact with the egg-yolk structure and could increase its protective effect against cold shock and freezing injury [27]. It has been proposed that Equex STM Paste improves post-thaw survival of spermatozoa by acting as a surfactant to stabilize cell membranes, particularly acrosome membranes, and to protect spermatozoa against the toxic effects of glycerol during the freezing-thawing process [38]. This substance, added to diluents at $0.5-1.5 \% \mathrm{v} / \mathrm{v}$, disperses egg yolk components and allows better interaction with the sperm plasma membrane surface [39]. Addition of EDTA to semen extenders as a chelating agent blocks the action of calcium as a mediator of sperm capacitation and the acrosome reaction [23].

Previous studies have reported that the use of Equex STM Paste on semen freezing extenders benefits postthaw motility [25], viability [22], and longevity [24] of ejaculated canine spermatozoa. Also, addition of Equex to freezing extenders protects the acrosomes of cat epididymal spermatozoa during the freezing-thawing process. In this regard, Ponglowhapan and Chatdarong [38], reported that supplementation with Equex Paste in the semen extender was effective for cryopreserving canine epididymal spermatozoa because it protected acrosome integrity against damage induced by freezing and prolonged post-thaw sperm motility during in vitro incubation at $37^{\circ} \mathrm{C}$. Moreover, Aisen et al. [23], reported higher percentages of cells with intact acrosome in the post-thawing evaluation of ram spermatozoa when extenders containing EDTA was used.

We observed that the use of additives could also reduce the agglutination level. In boar, the incidence and degree of agglutination was affected by individual, ejaculatory and seasonal variations. It was also reported that sperm agglutination exerted a negative effect on motility but was largely reduced after dilution in semen extender, although it did not interfere with fertility results [21].

Egg yolk was routinely included in semen crypreservation protocols of domestic as well as wild species and seemed to help spermatozoa in resisting against cold shock $[40,41]$.

Egg yolk concentrations of 15\% (Hokkaido brown bear [7]) and 20\% (Japanese black bear [42]) have been used for freezing the bears semen. In our study, $20 \%$ egg yolk appeared as the most suitable egg yolk concentration for preserving brown bear spermatozoa, since it improves sperm motility, viability and acromo- somal status. Although some authors have reported negative effects of high concentrations of egg yolk on the preservation of motility and acrosome integrity (in Mohor gazelle [16]) we noted that it has been suggested that egg yolk's effects differ depending on the composition of the extender buffer [43] .Thus, the higher egg yolk concentration in a raffinose-based diluent resulted in a better preservation of motility and membrane integrity during the cooling of spermatozoa in Cuvier's gazelle [14] or in red deer [44].

Concentrations of glycerol ranging from 2 to $10 \%$ have been applied to cryopreserve mammalian spermatozoa [31]. For ungulates, optimal glycerol concentration for sperm cryopreservation usually ranges between $4 \%$ and $8 \%$ [39]. Glycerol concentrations used in sperm of different bear species vary between $4-8 \%[7,8,9$, $10,11,19]$. In this regard, our results coincide with those for the glycerol concentrations used in other ursids. Frozen-thawed sperm motility was influenced by different glycerol concentrations in some species, (stallion [44]; boar [45], ram [46] and Rhesus monkeys [47]. However, in Japanese black bear sperm motility was not affected by different glycerol concentrations (4$12 \%$ ) but the percentage of viability and intact acrosomes were higher for sperm frozen with 4 and $6 \%$ glycerol [17]. In our study, sperm motility, viability, acrosome integrity and mitochondrial activity were not significantly affected by the two glycerol concentrations. This suggested that the adequate glycerol concentration for freezing brown bear sperm could be between $4-8 \%$.

The role of extender osmolality on the quality of frozen-thawed brown bear spermatozoa was analyzed in present study. Once we observed the benefits of using additives and the most suitable glycerol and egg yolk concentrations (additives supplementation, glycerol-8\%, egg yolk-20\%), we prepared two extenders with this composition adjusted to 300 and $320 \mathrm{mOsm} / \mathrm{kg}$ (E300 and E320). For brown bear spermatozoa, extender E300 showed significantly higher results for some kinetic parameters (VAP, VCL, VSL, and ALH).

Environment osmolality is a significant factor when cryopreserving semen. Not only do anisoosmotic solutions induce cellular stress, but they also influence the outcome of the cryopreservation process. However, this influence could be positive since the osmolality of the extender modifies water flux through spermatozoa membrane [48]. In this regard, we must consider the average osmolality of the sperm samples used in this experiment $(308 \pm 38 \mathrm{mOsm} / \mathrm{kg})$ to interpret our results.
306

307

308

309

310

311

312

313

314

315

316

317

318

319

320

321

322

323

324

325

326

327

328

329

330

331

332

333

334

335

336

337

338

339

340

341

342

343

344

345

346

347

348

349

350

351

352

353

354

355

356

357 
According to this, the use of an E300 extender with an osmolality similar to that expected for the sample might be the best option. So, the hypothesis that a nearly isoosmotic extender could provide the best environment for brown bear spermatozoa was confirmed. This finding did not agree with reports documented in other species (bull [49], ram [23], and deer [34]) which showed that moderately hyperosmotic extenders might protect spermatozoa better than isoosmotic ones. In this context, spermatozoa of each species are affected in a different way by changes in the osmolality of the media, so this is a decisive factor to obtain acceptable cryopreservation results [49]. For instance, whereas osmotic tolerance of ram sperm in hypoosmotic conditions is much lower than bull sperm, it is higher than boar sperm [50]. Several reports have revealed information on the osmotic effects of glycerol addition and removal on post-thawing motility and acrosome integrity of ram spermatozoa [51].

Considering the lack about knowledge of sperm cryobiology in bear, our findings can contribute to developing specific extenders for an efficient cryopreservation of brown bear spermatozoa.

In conclusion, we found that the best extender for cryopreserving brown bear sperm was a TES-TrisFructose buffer with an osmolality of $300 \mathrm{mOsm} / \mathrm{kg}$, and supplemented 20\% egg-yolk, 4-8\% glycerol and additives (EDTA and Equex paste). In order to further refine extender composition, new studies must be developed in order to improve cryopreservation results.

\section{Acknowledgments}

This work was supported in part by CICYT (CGL 2004-02178/BOS), CICYT (CGL 2007-63748/BOS) and CANTUR S.A.

\section{References}

[1] Holt WV, Pickard AR. Role of reproductive technologies and genetic resource banks in animal conservation. Rev Reprod. 1999;4:143-150.

[2] Yoshida M. Conservation of sperms: current status and new trends. Anim Reprod Sci. 2000;6061:349-55.

[3] Anel L, Martinez-Pastor F, Alvarez M, Garcia-Macias V, Borragan S, Celada M, Martinez F, Chamorro CA, Herraez P, Anel E, Paz P. Basis for the establishment of germplasm banks for brown bear: spermatology. Reprod Domest Anim 2005;40:335.

[4] Leibo SP, Songsasen N. Cryopreservation of gametes and embryos of non-domestic species. Theriogenology 2002;57: 303-26.

[5] Anel L, Alvarez M, Martinez-Pastor F, Gomes S, Nicolas M, Mata M, Martinez AF, Borragan S, Anel E, de PP. Sperm cryopreservation in brown bear (Ursus arctos): preliminary aspects. Reprod Domest Anim1 2008a;43:(Suppl 4)9-17.

[6] Gilmore JA, McGann LE, Ashworth E, Acker JP, Raath JP, Bush M, Critser JK. Fundamental cryobiology of selected African mammalian spermatozoa and its role in biodiversity preservation through the development of genome resource banking. Anim Reprod Sci 1998;53:277-97.

[7] Ishikawa A, Matsu M, Sakamoto H, Katagiri S, Takahashi Y. Cryopreservation of the semen collected by electroejaculation from the Hokkaido brown bear (Ursus arctos yesoensis). J Vet Med Sci 2002;64:373-6.

[8] Okano T, Murase T, Tsubota T. Electroejaculation and semen cryopreservation of free-ranging Japanese black bears (Ursus thibetanus japonicus). J Vet Med Sci 2004;66:1371-6.

[9] Seager SWJ, Dulensek EP, He G, Schaller GB. Giant panda (Ailuropoda melanoleuca) semen collection, evaluation and freezing in Southwest China. In: Proceedings of the $15^{\text {th }}$ Annual Meeting of the Society for Cryobiology. Tokyo, Japan, pp. 123-126. 1987.

[10] Spindler RE, Huang Y, Howard JG, Wang P, Zhang H, Zhang G, Wildt DE. Acrosomal integrity and capacitation are not influenced by sperm cryopreservation in the giant panda. Reproduction 2004; 127:547-56.

[11] Zhang M, Tang H, Shen G, Zhou B, Wu Z, Peng Z, Zhang J, Yan J, Xia G. Atrial natriuretic peptide induces an acrosome reaction in giant panda spermatozoa and enhances their penetration of salt-stored porcine oocytes. Theriogenology 2005;64: 1297-308.

[12] Salamon S, Maxwell WM. Storage of ram semen. Anim Reprod Sci 2000;62:77-111.

[13] Verstegen JP, Onclin K, Iguer-Ouada M. Long-term motility and fertility conservation of chilled canine semen using egg yolk added Tris-glucose extender: in vitro and in vivo studies. Theriogenology 2005;64:720-33.

[14] Garde JJ, del Olmo A, Soler AJ, Espeso G, Gomendio M, Roldan ERS. Effect of egg yolk, cryoprotectant, and various sugars on semen cryopreservation in endangered Cuvier's gazelle (Gazella cuvieri). Animal Reprod Sci 2008;108:384-401.

[15] Holt WV, Abaigar T, Jabbour HN. Oestrus synchronization, semen preservation and arti.cial insemination in the Mohor Gazelle (Gazella dama mhorr) for the establishment of a genome resource bank programme. Reprod Fertil Dev 1996;8: 1215-22.

[16] Ritar AJ, Salamon S. Effects of month of collection, method of processing, concentration of egg yolk and duration of frozen storage on viability of Angora goat spermatozoa. Small Rumin Res 1991;4:29-37.

[17] Okano T, Nakamura S, Komatsu T, Murase T, Miyazawa K, Asano M, Tsubota T. Characteristics of frozen-thawed spermatozoa cryopreserved with different concentrations of glycerol in captive Japanese black bears (Ursus thibetanus japonicus). J Vet Med Sci 2006b;68:1101-4.

[18] Fahy GM. The relevance of cryoprotectant "toxicity" to cryobiology. Cryobiology 1986;23:1-13.

[19] Anel L, Martinez F, Alvarez M, Anel E, Boixo JC, Kaabi M, Paz P, Chamorro C, Herraez P. Post-mortem spermatozoa recovery and freezing in Cantabric brown bear (Ursus arctos): a preliminary report. Theriogenology 1999;51:277.

[20] Kojima E, Tsuruga H, Komatsu T, Murase T, Tsubota T, Kita I. Characterization of semen collected from beagles and captive Japanese black bears (Ursus thibetanus japonicus). Theriogenology 2001;55:717-31. 
[21] Bollwein H, Petschow K, Weber F, Leiding C, Stolla R. The incidence of agglutination and its influence on sperm quality and fertility of boar semen. Berl Munch Tierarztl Wochenschr 2004; 117:327-33.

[22] Rota A, Strom B, Linde-Forsberg C, Rodriguez-Martinez H. Effects of equex STM paste on viability of frozen-thawed dog spermatozoa during in vitro incubation at 38 degrees $\mathrm{C}$. Theriogenology 1997;47:1093-101.

[23] Aisen EG, Alvarez HL, Venturino A, Garde JJ. Effect of trehalose and EDTA on cryoprotective action of ram semen diluents. Theriogenology 2000;53:1053-61.

[24] Peña AI, Lugilde LL, Barrio M, Herradon PG, Quintela LA. Effects of Equex from different sources on post-thaw survival, longevity and intracellular $\mathrm{Ca} 2+$ concentration of dog spermatozoa. Theriogenology 2003;59:1725-39.

[25] Alhaider AK, Watson PF. Cryopreservation of dog semen: the effects of Equex STM paste on plasma membrane fluidity and the control of intracellular free calcium. Anim Reprod Sci 2009;110:147-61.

[26] Axner E, Hermansson U, Linde-Forsberg C. The effect of Equex STM paste and sperm morphology on post-thaw survival of cat epididymal spermatozoa. Anim Reprod Sci 2004;84:179-91.

[27] Pursel VG, Schulman LL, Johnson LA. Effect of Orvus ES Paste on acrosome morphology, motility and fertilizing capacity of frozen-thawed boar sperm. J Anim Sci 1978;47:198-202.

[28] Martin JC, Klug E, Gunzel AR. Centrifugation of stallion semen and its storage in large volume straws. J Reprod Fertil. 1979; Suppl 47-51.

[29] Arriola J, Foote RH. Glycerolation and thawing effects on bull spermatozoa frozen in detergent-treated egg yolk and whole egg extenders. J Dairy Sci. 1987:70:1664-70.

[30] Cheng FP, Wu JT, Chan JP, Wang JS, Fung HP, Colenbrander B, Tung KC. The effect of different extenders on post-thaw sperm survival, acrosomal integrity and longevity in cryopreserved semen of Formosan Sika deer and Formosan Sambar deer. Theriogenology 2004;61:1605-16.

[31] Agca Y, Critser JK. Cryopreservation of spermatozoa in assisted reproduction. Semin. Reprod. Med. 2002;20:15-23.

[32] Anel L, de PP, Alvarez M, Chamorro CA, Boixo JC, Manso A, Gonzalez M, Kaabi M, Anel E. Field and in vitro assay of three methods for freezing ram semen. Theriogenology 2003; 60:1293-308.

[33] Alvarez M, Martinez-Pastor F, Garcia-Macias V, Borragan S, Celada M, Bernardo J, Gonzalez N, Alves S, Anel L. Epididymal sperm cryopreservation of one Somalia wild ass (Equus africanus somaliensis) using 6 different extenders. Reprod Fertil Dev 2006;18:215

[34] Martinez-Pastor F, Martinez F, Garcia-Macias V, Esteso MC, Anel E, Fernandez-Santos MR, Soler AJ, de PP, Garde J, Anel L. A pilot study on post-thawing quality of Iberian red deer spermatozoa (epididymal and electroejaculated) depending on glycerol concentration and extender osmolality. Theriogenology 2006;66:1165-72.

[35] Anel E, Borragan S, Alvarez M, Nicolas M, Gomes-Alves S, Mata M, Boixo JC, Anel L. Sperm charateristics in ejaculated and epididymal Blue wildebeest (Connochaetes taurinus). Reprod Domest Anim 2008b;43:Suppl 3209.

[36] Garcia-Macias V, Martinez-Pastor F, Alvarez M, Borragan S, Chamorro CA, Soler AJ, Anel L, de Paz P. Seasonal changes in sperm chromatin condensation in ram (Ovis aries), Iberian red deer (Cervus elaphus hispanicus), and brown bear (Ursus arctos). J Androl 2006;27:837-46.

[37] Mortimer D. Computerized semen analysis. Fertil Steril 1988; 49:182-5.

[38] Ponglowhapan S, Chatdarong K. Effects of Equex STM Paste on the quality of frozen-thawed epididymal dog spermatozoa. Theriogenology 2008;69:666-72.

[39] Watson PF, Holt WV. Cryobanking the Genetic Resource: Wildlife Conservation for the Future? London: Taylor and Francis. 2001.

[40] White IG. Lipids and calcium uptake of sperm in relation to cold shock and preservation: a review. Reprod Fertil Dev 1993; 5:639-58.

[41] Fernandez-Santos MR, et al. Effects of egg yolk and cooling rate on the survival of refrigerated red deer (Cervus elaphus hispanicus) epididymal spermatozoa. Reprod Domest Anim 41.2 (2006): $114-18$.

[42] Okano T, Murase T, Yayota C, Komatsu T, Miyazawa K, Asano M, Tsubota T. Characteristics of captive Japanese black bears (Ursus thibetanus japonicus) semen collected by electroejaculation with different voltages for stimulation and frozen-thawed under different conditions. Anim Reprod Sci 2006a;95:134-43.

[43] Watson PF. Electroejaculation, semen characteristics and semen preservation of the brindled gnu. J Reprod Fertil 1976;47: 123-26.

[44] Cochran JD, Amann RP, Froman DP, Pickett BW. Effects of centrifugation, glycerol level, cooling to 5 degrees $\mathrm{C}$, freezing rate and thawing rate on the post-thaw motility of equine sperm. Theriogenology 1984;22:25-38.

[45] Buhr MM, Fiser P, Bailey JL, Curtis EF. Cryopreservation in different concentrations of glycerol alters boar sperm and their membranes. J Androl 2001;22:961-9.

[46] Fiser PS, Fairfull RW. The effect of glycerol concentration and cooling velocity on cryosurvival of ram spermatozoa frozen in straws. Cryobiology 1984;21:542-51.

[47] Si W, Zheng P, Li Y, Dinnyes A, Ji W. Effect of glycerol and dimethyl sulfoxide on cryopreservation of rhesus monkey (Macaca mulatta) sperm. Am J Primatol 2004;62:301-6.

[48] Fernandez-Santos MR, Martinez-Pastor F, Garcia-Macias V, Esteso MC, Soler AJ, de Paz P, Anel L, Garde JJ. Extender osmolality and sugar supplementation exert a complex effect on the cryopreservation of Iberian red deer (Cervus elaphus hispanicus) epididymal spermatozoa. Theriogenology 2007;67: 738-53.

[49] Liu Z, Foote RH, Brockett CC. Survival of bull sperm frozen at different rates in media varying in osmolarity. Cryobiology 1998;37:219-30.

[50] Varisli O, Uguz C, Agca C, Agca Y. Motility and acrosomal integrity comparisons between electro-ejaculated and epididymal ram sperm after exposure to a range of anisosmotic solutions, cryoprotective agents and low temperatures. Anim Reprod Sci 2009;110:256-68.

[51] Gao DY, Liu J, Liu C, McGann LE, Watson PF, Kleinhans FW, Mazur P, Critser ES, Critser, JK. Prevention of osmotic injury to human spermatozoa during addition and removal of glycerol. Hum Reprod 1995;10:1109-22. 